\title{
Lyme disease in paediatrics
}

\author{
B Cryan, D J M Wright
}

The cluster of 39 children with a presumptive diagnosis of juvenile rheumatoid arthritis in Connecticut, around the town of Old Lyme, initiated the research which eventually led to the arthritis being named Lyme arthritis. ${ }^{1}$ The association with a multisystem illness then caused the syndrome to be redefined as Lyme disease. Epidemiologically, an infectious aetiology appeared probable, with ticks as likely vectors for the disease. Clinically, a skin rash, erythema migrans, preceded the development of the arthritis. The skin rash had been first described in Scandinavia in 1913 and associated with tick bites. ${ }^{2}$ Some patients presented with Bannwarth's syndrome, a meningopolyneuritis associated with tick bites, described in Europe as early as $1941 .^{3}$ A possible causative organism, Borrelia burgdorferi, was isolated from a tick in 1982. ${ }^{4}$ This hypothesis was substantiated when the spirochaete was grown from blood, skin lesions, and cerebrospinal fluid (CSF) of patients with Lyme disease, and the disease was reproduced in rabbits, fulfilling Koch's postulates. ${ }^{56}$ Since then the disease has been recognised in many American states, Northern Europe, Russia, China, and Japan. ${ }^{7}$ It has also been reported in the southern hemisphere in Australia. $^{7}$

\section{Transmission}

$B$ burgdorferi is transmitted by the ticks of the genus ixodes. Ixodes dammini is most frequently implicated in the eastern USA. In the western USA and Japan I pacificus predominates. $I$ ricinus acts as the vector in Europe with I persulcatus in Asiatic and European Russia. ${ }^{8} 9$ The nymphal ticks become infected by $B$ burgdorferi while feeding on small mammals such as the white foot mouse, which act as reservoirs of the spirochaete. The natural hosts of mature ticks are large mammals such as deer. Humans are incidentally bitten when they enter a tick infected area, usually forest or scrub land. ${ }^{10}$ Children playing in such areas would be at particular risk of infection. The frequency of infection after a tick bite depends on a number of factors, such as the prevalence of $B$ burgdorferi infection in the ticks, the duration of tick attachment, and the number of tick bites. In an English study of forestry workers, $25 \%$ had serological evidence of $B$ burgdorferi exposure, and $5 \%$ symptoms attributable to Lyme disease. ${ }^{11}$ These workers may have had multiple bites whereas positive Lyme serology was recorded in $20 \%$ of Austrian and $7 \%$ of Irish populations who reported single bites. ${ }^{12} 13$ Another English study reported positive serology in $12 \%$ of a population comprising farmers, gamekeepers, and forestry workers. ${ }^{14}$

\section{Epidemiology}

Since 1982 the number of cases of Lyme disease in the USA has increased from 500 to over $\mathbf{4 5 0 0}$ in 1988. The highest incidence is in children of less than 15 years and in adults of $25-44$ years. ${ }^{15}$ Females were infected in $51 \%$ of cases. Data on file at the Charing Cross Lyme Disease Reference Laboratory records approximately 600 cases per year or 0.39 cases per 100000 people. Most seropositivity is detected in middle aged patients, and the number of males is equal to that of females. In the eastern USA most cases occur in the summer months, ${ }^{10} 15$ which follows the period of maximal host seeking activity of nymphal ticks in May and June. ${ }^{16}$ In the western USA, cases are most common in spring. ${ }^{15}$ At Charing Cross there are two peaks, one in spring and one in autumn. Most Irish cases have come to medical attention in the autumn.

\section{Clinical features}

Typically, the clinical features of Lyme disease occur in three stages. ${ }^{17}$ There is considerable overlap between stages of the disease, and features of late Lyme disease may develop without any history of early disease. One of the 'unsolved mysteries' of Lyme disease is that there have been no outbreaks of arthritis reported since the initial 'cluster' in Connecticut.

The characteristic rash, erythema migrans, develops 2-30 days after the tick bite. This expanding lesion is centred on the insect bite and spreads outwards over a period of weeks. It is seen in up to $50 \%$ of patients and is occasionally due to multiple bites. ${ }^{18}$ Non-specific constitutional symptoms may occur at this stage: malaise, anorexia, lethargy, arthralgia, headache, roseola skin rash, abdominal pain, cough, and sore throat are common complaints. Patients, especially children, may be feverish.

The second stage of Lyme disease develops 1-4 months after infection. These patients tend to come to medical attention in the autumn or winter. Lymphocytosis cutis occurs in $1 \%$ of European cases but has not been reported in the USA. This lesion is a firm red to purple nodule or plaque. It develops on the ear lobe in children and on the nipple and areola in 
adults. ${ }^{18}$ Pathologically there is a dense dermal nodular lymphocytic infiltrate involving $B$ and $T$ lymphocytes. Infrequently, similar lymphocyte infiltrates, at the base of the brain in Lyme borreliosis, have been misdiagnosed in children as B-cell lymphomas.

Central nervous involvement is common. Lymphocytic meningitis, cerebellar signs, cranial polyneuropathy, and radiculopathy have been reported. The differentiation from GuillainBarré syndrome may be difficult, but in neuroborreliosis the lymphocyte count is usually greater than 50 cells $/ \mathrm{mm}^{3}$ and oligoclonal bands may be seen. Encephalitis, often clinically indistinguishable from herpes simplex encephalitis, may occur. Outside the UK one must consider other arthropod-borne encephalopathies in such cases. In an Austrian study of 21 children seropositive for Lyme disease, 17 had central nervous system involvement, three had arthritis, and one had skin symptoms. ${ }^{19}$ In this study and in a Swedish report aseptic meningitis and seventh nerve palsies were the commonest neurological features described. ${ }^{19} 20$ Pain in joints and soft tissues and rarely asymmetrical large joint arthritis may occur at this stage. These episodes are brief and recurrent. ${ }^{17} \mathrm{~A}$ self limiting myocarditis, which may necessitate the insertion of a transvenous pacemaker, infrequently presents during this phase of the illness. Bradycardia is not otherwise a feature of the disease. Iritis or panophthalmitis has also been reported, as has isolated inflammation of peripheral muscles. ${ }^{17}$

In the third stage, joint disease is most common. As many as $10 \%$ of patients may progress to a chronic erosive arthritis. ${ }^{1}$ In an American study of Lyme arthritis in 43 children $^{21}$ the mean age was $7 \cdot 8$ years and the male:female ratio 7:1. The knee was involved in 41 patients, the elbow in eight, the hip or ankle in four, and the wrist in two. ${ }^{21}$

At this stage in older patients demyelinating encephalopathy, polyneuritis, and memory impairment may become manifest. ${ }^{1}$ Acrodermatitis chronica atrophicans is the characteristic skin rash of this phase of the disease. Initially this is a violaceous and often oedematous area of skin in plaques or nodules, which later atrophies. It resembles but is distinct from scleroderma. ${ }^{17} 18$ Acrodermatitis is unusual in childhood Lyme borreliosis but at least two cases have been described. ${ }^{22}$ Eosinophilic fasciitis is a rare complication. ${ }^{17}$

As many as $30 \%$ of patients do not demonstrate erythema migrans or other signs of early disease before presenting with late complications. ${ }^{23}$ In European Lyme disease, joint manifestations are reported to be less common than in the USA. Conversely, in Europe nervous involvement tends to be more prominent. ${ }^{2425}$ In North American Lyme disease, erythema migrans is more often multiple than in Europe. Recent reports suggest that these differences may be less extreme. ${ }^{1326}$

The isolation of $B$ burgdorferi from the blood has raised the possibility of transplacental transfer of the organism. To date, borreliae have been isolated from one stillbirth and one newborn infant but congenital abnormalities resulting from Lyme disease during pregnancy have not been unequivocally demonstrated. ${ }^{27}$ The abnormalities that have been recorded were associated with serological evidence of infection in retrospective studies. ${ }^{28}$

\section{Laboratory diagnosis}

The laboratory diagnosis of Lyme disease is difficult. The organism has been grown from infected tissues such as skin and body fluids, including CSF. ${ }^{29}$ Culture is an insensitive technique in most hands and not suitable for routine diagnostic use. Visualisation of the pathogen in infected tissue has similar limitations. ${ }^{30}$ For these reasons serological techniques have been employed as routine diagnostic aids.

Indirect immunofluorescent assay (IFA) techniques were initially used to detect antibodies $B$ burgdorferi but recently, as demand for tests has increased, enzyme linked immunosorbent (ELISA) methodologies have become popular. Such tests can be automated, allow objective test reporting, and are easier to standardise than IFA methods. ${ }^{31}$

Initial antibody responses are directed against the unsheathed flagellar proteins. ${ }^{31} \mathrm{~A}$ rise in IgM antibodies directed against a $41 \mathrm{kDa}$ flagellar antigen can be detected in most patients two to four weeks after infection. This response peaks at six to eight weeks. Assays which detect IgM response to such proteins are very useful early in the disease. ELISAs which use purified flagellae or flagella enriched preparations of whole $B$ burgdorferi as antigens have increased sensitivity in early disease. ${ }^{32} 33$ Later in the course of the illness antibodies directed against proteins in the outer surface membranes (OSP), such as the $34 \mathrm{kDa}$ OSP B or the $31 \mathrm{kDa}$ OSP $A$, are detected. ${ }^{31}$ As $B$ burgdorferi shares many antigenic determinants with other bacteria, sera may contain antibodies which cross react in the IFA or ELISA assays described. ${ }^{31}{ }^{32}$ False positive results can also occur in patients with connective tissue disorders. ${ }^{34}$ Therefore further definition of the immune response by immunoblotting is a necessary confirmatory procedure if such tests provide positive results. Immunoblot patterns in children are similar to those of adults. ${ }^{35}$ At the Charing Cross Lyme Disease reference laboratory $11 \%$ of the ELISA specimens that are weakly positive and a third of those that are strongly positive are confirmed by immunoblot. False negative results have also been reported: as many as one in three patients with erythema migrans are seronegative on initial testing, ${ }^{23}$ and may become seropositive on further testing. Antibiotic treatment early in the illness may abrogate the antibody response to $B$ burgdorferi. ${ }^{36}$

A suitable test system would include a sensitive screening test, such as an ELISA which uses whole $B$ burgdorferi or a flagella enriched preparation as the antigen. All positive results would then be checked by immunoblotting. Where clinically indicated, specimen testing would have to be repeated. In most instances serum would be a suitable specimen, but if neurological syndromes are being investigated CSF should also be examined. In one study nine 
patients with neurological syndromes suggestive of Lyme disease had serum which was positive by ELISA, but only one had a CSF positive by ELISA and immunoblot and also evidence of intrathecal antibody production. ${ }^{13}$

In interpreting the laboratory results one must be aware that a proportion of the population will have serological evidence of previous exposure to $B$ burgdorferi which may be unrelated to their current symptoms. Seropositivity rates of approximately $25 \%$ are detected in high risk populations such as forestry workers or orienteers. ${ }^{1137}$ Clinical symptoms attributable to Lyme disease were detected in $5 \%$ of the forestry workers and $0.8 \%$ of the orienteers.

Modern advances in molecular genetics and the application of techniques such as the polymerase chain reaction (PCR) may resolve some of these diagnostic problems. A PCR assay using a highly conserved area of $B$ burgdorferi chromosomal DNA was able to detect fewer than five copies of complementary DNA. The assay did not cross react with $B$ hermsi or eukaryotic DNA. ${ }^{38}$ The same authors expanded their primer range and were able to differentiate between $B$ burgdorferi of European or American origin. ${ }^{39}$ Using a PCR method, $B$ burgdorferi DNA was detected in the urine of four of eight patients with clinical syndromes suggestive of Lyme disease. ${ }^{40}$ If there is a high prevalence of $B$ burgdorferi genetic material in the urine of infected patients, detection may simplify the laboratory diagnosis of Lyme borreliosis. By such techniques we may be able to detect these organisms in body tissues and further define the pathogenesis of Lyme disease. Classifying borrelia by PCR may provide valuable epidemiological information which would have especial relevance to vaccine development strategies.

\section{Treatment}

The aims of treatment in Lyme borreliosis are (a) to speed the resolution of the patients presenting illness and (b) to stop the progression to major long term sequelae.

It is probably best to avoid prophylactic antibiotics for people who have been bitten by ticks, as the likelihood of an individual developing Lyme disease is small and there is always a risk of an unexpected allergic reaction to antibiotics. $^{41}$ Insect repellents to prevent the attachment of the tick are more practical. Nursing and medical staff attending patients with Lyme disease do not require prophylaxis as person to person transmission is unknown.

A particular problem of Lyme disease is that the clinical outcome cannot always be predicted from the sensitivity of the causative bacterium to antimicrobial agents in vitro. $B$ burgdorferi is sensitive to a variety of common antibiotics, such as benzylpenicillin, erythromycin, tetracycline, amoxycillin, ceftriaxone, and cefotaxime. Antibiotics such as metronidazole, rifampicin, and sulphonamides have no role in the therapy of Lyme disease. The new quinolones and the aminoglycosides are likewise ineffective at clinical dosages. ${ }^{42-44}$

An oral agent is preferable in the treatment of early Lyme disease. Erythema migrans and its associated symptoms resolved significantly earlier in patients given tetracycline or penicillin than in those treated with erythromycin. ${ }^{45}$ None of 39 patients treated with tetracycline developed major late complications but $8 \%$ of the 40 patients given penicillin, and $14 \%$ of the 29 erythromycin treated patients did. All drugs were used in a dosage of $250 \mathrm{mg}$ four times daily for 10 days. In a more recent study, no statistically significant differences were detected in the responses to tetracycline or penicillin therapy in erythema migrans. The tetracycline treated patients, however, developed fewer long term major complications, and fewer of them required further courses of antibiotic therapy. ${ }^{46}$

Oral doses of tetracycline, $250 \mathrm{mg}$ four times a day, produce peak serum concentrations four times the minimum inhibitor concentration (MIC), whereas phenoxymethylpenicillin in oral doses of $500 \mathrm{mg}$ four times a day produces serum concentrations equal to the $\mathrm{MIC}^{47}$ Doxycycline in a dosage of $100 \mathrm{mg}$ twice daily may be a convenient alternative. Amoxycillin combined with probenecid has also been used successfully to treat early Lyme disease. A recent study compared amoxycillin and probenecid ( $500 \mathrm{mg}$ of each three times) to doxycycline (100 mg twice daily). All patients had early skin manifestations of Lyme disease and the duration of therapy was 21 days in each case. ${ }^{48}$ In all patients the erythema migrans resolved and none developed major late sequelae. Symptoms after treatment such as fatigue, headache and arthralgia, developed in $15 \%$ of patients and persisted for up to three months. Such symptoms have been noted by other authors and resolve. They are twice as likely to occur in patients with disseminated early disease than in those with single lesions. ${ }^{49}$

The duration of treatment depen i in the severity of the illness: 10 days is thougnt to be adequate in mild cases with skin manifestations but 21 days may be more appropriate in cases of disseminated disease. Longer periods of treatment do not reduce the incidence of major or minor late sequelae. ${ }^{49}$ In children less than 9 years old tetracyclines are contraindicated. In such cases amoxycillin and probenecid orally for 10 to 21 days are the drugs of choice. Erythromycin is a less effective alternative for penicillin sensitive children. In children older than 9 years, oral doxycycline is the most appropriate therapy. Amoxycillin with probenecid is an alternative.

The classical treatment for the neurological signs of Lyme disease was high dose parenteral penicillin.50 In patients who mainfest an uncomplicated Bell's palsy the outcome is usually favourable, and unless symptoms of meningitis or radiculitis are present oral administration is probably adequate. In a Swedish study of doxycycline treatment for neurological Lyme disease, doxycycline concentrations of 0.2 to $1 \mathrm{mg} / \mathrm{l}$ were obtained in the CSF during a regimen of $100 \mathrm{mg}$ twice daily, all patients had a favourable outcome. ${ }^{51}$ On a treatment schedule of $200 \mathrm{mg}$ twice daily, CSF concentrations of $0.6-1.9 \mathrm{mg} / \mathrm{l}$ were achieved. The MIC of $B$ burgdorferi was exceeded in the CSF after the 
first day of this dosage, but three to five days of treatment was needed to achieve comparable levels on the lower dosage regimen. ${ }^{52}$

Treatment for patients with meningitis or radiculitis should be more aggressive. Parenteral penicillin in doses of 20 megaunits daily for 10 days has been used as standard treatment for neuroborreliosis. Results have been disappointing and the isolation of $B$ burgdorferi from the CSF of a patient being treated with penicillin underlines the inability of penicillin to kill spirochaetes which may survive under suboptimal conditions. ${ }^{53}$ From the results of in vitro studies, third generation cephalosporins appear effective. ${ }^{42}{ }^{44}$ Ceftriaxone has a half life of 8.5 hours. ${ }^{54}$ In the absence of meningitis it crosses the blood-CSF barrier to give CSF concentrations $1.5 \%$ of those in serum. Two to four hours after an intravenous infusion of $2 \mathrm{~g}$ of ceftriaxone, CSF concentrations three to four times the MIC for $B$ burgdorferi may be obtained. ${ }^{55}$ It has been used successfully and proved superior to parenteral penicillin in late neuroborreliosis. ${ }^{56}$

Though experience with ceftriaxone in Lyme meningitis or radiculitis is limited it appears to be a useful agent. ${ }^{5758} \mathrm{An}$ association has been demonstrated between the use of ceftriaxone and the development of biliary concretions. This antibiotic is as yet unlicensed in the UK. ${ }^{59}$ As an alternative cefotaxime may be used and is equally effective. ${ }^{58}$ The duration of treatment depends on the clinical response and usually varies between 21 and 30 days. In a patient treated for 10 days with parenteral ceftriaxone $B$ burgdorferi was isolated from the CSF 7.5 months after treatment. ${ }^{56}$ Recovery from meningitis is relatively rapid but radicular signs may persist for up to 24 months. ${ }^{49}$

Lyme encephalopathy is probably best treated by parenteral ceftriaxone, or by benzylpenicillin as a less effective alternative. ${ }^{56} 60$ There is a case report of the successful use of cefotaxime in Lyme encephalitis. ${ }^{61}$

In patients with Lyme chronic synovitis, treatment failure rates of up to $50 \%$ have been reported, especially if erosive changes are present. ${ }^{62}$ Ceftriaxone is superior to penicillin, with therapeutic success rates of over $90 \% .{ }^{56} 60$ Oral doxycycline or, alternatively amoxycillin with probenecid, have been used to treat these patients, with success rates of $72 \%$ and $61 \%$ respectively. ${ }^{63}$

The use of corticosteroids in patients with chronic synovitis increases the risk of antibiotic failure and they are best avoided. ${ }^{56}$ The development of chronic synovitis with a poor response to therapy has been associated with HLA DR4 and HLA DR2 alleles. ${ }^{64}$

Jarisch-Herxheimer reactions are encountered in $14 \%$ of patients treated for early Lyme disease. They occur within 2-4 hours of starting treatment and are more common in severe disease. $^{45}$ Meptazinol unlike adrenocorticosteroids, has been shown to ameliorate such reactions in relapsing fever. ${ }^{65}$ Meptazinol may be useful in cases of Lyme disease involving vital organs.

In conclusion, Lyme disease is a serious disorder with potential immediate and long term morbidity and mortality. It occurs in many parts of the world and affects all ages. The diagnosis of Lyme borreliosis should be considered in any unusual neuropathy or arthropathy. Laboratory tests may confirm the diagnosis but must be interpreted with care. Long term complications may occur if it is not recognised and treated effectively. Oral tetracycline, if the patient is older than 9 years, is recommended for early Lyme disease. Younger children should receive amoxycillin and probenecid. In the late stages, ceftriaxone or cefotaxime is more effective than penicillin.

In future, vaccines may provide protection against Lyme borreliosis. Recent evidence in murine models of $B$ burgdorferi: infection suggests that outer membrane proteins may be important in this regard. ${ }^{66}$

1 Steere AC, Malawista SE, Snydman DR, et al. Lyme arthritis: an epidemic of oligoarticular arthritis in children and adults in three Connecticut communities. Arthritis Rheum 1977; in three 7 . 17 .

2 Afzelius A. Report to the Verhandlungen der Dermatologishen Gessellschaft zu Stockholm. Arch Dermatol Syph 1910;101: 405-6.

3 Bannwarth A. Chronische lymphocytäre meningitis, enzündliche polyneuritis und 'rheumatismus' ein beitrag zum problem 'allergie und nervensystem'. Archiv für Psychiatrie Nervenkrankheiten 1941;113:284-376.

4 Burgdorfer W, Barbour AG, Hayes SF, Benach JL, Grunwald E, Davis JP. Lyme disease-a tick borne spirochetosis? Science 1982;216:1317-9.

5 Benach JL, Bosler EM, Hanrahan JP, et al. Spirochetes isolated from the blood of two patients with Lyme disease. N Englf Med 1983;308:740-2.

6 Steere AC, Grodzicki RL, Kornblatt AN, et al. The spirochetal aetiology of Lyme disease. $N$ Engl 7 Med 1983; 308:733-40.

7 Schmid GP. The global distribution of Lyme disease. Rev Infect Dis 1985;7:41-50.

8 Parke A. From new to old England: the progress of Lyme disease. $B M \mathcal{F}$ 1987;294:525-6.

9 Kawabata M, Bara S, Iguchi K, Yamaguti N, Russell H. Lyme disease in Japan and its possible incriminating tick Lyme disease in Japan and its possible incriminatin
vector Ixodes persulcatus. $\mathcal{F}$ Infect Dis 1987;5:854.

10 Lastavica CC, Wilson ML, Berardi VP, Spielman A Deblinger RD. Rapid emergence of a focal epidemic of Lyme disease in coastal Massachusetts. N Engl f Med 1989; 320:133-7.

11 Guy EC, Martyn CN, Bateman DE, Heckels JE, Lawton NF. Lyme disease: prevalence and clinical importance of borrelia burgdorferi species specific IgG in forestry workers. Lancet 1989;i:484-6.

12 Schmutzhard E, Stane K, Pletchette $M$, et al. Infections following tick bites. Tick-borne encephalitis and Lyme borreliosis-a prospective study from Tyrol. Infection 1988 ; 16:269-72.

13 Cryan B, Cutler SJ, Wright DJM. Lyme disease in Ireland. Ir Med $\mathcal{f}$ (in press)

14 Baird AG, Gilies JCM, Bone FJ, Dale BAS, Miscambell NT. Prevalence of antibody indicating Lyme disease in farmers Prevalence of antibody indicating Lyme
in Wigtownshire. BMF 1989;299:836-7.

15 Centers for Disease Control. Lyme disease-United States 1987 and 1988. MMWR 1989;38:668-72.

16 Piesman J, Mather TN, Dammin GJ, Telford SR, Lastavica $\mathrm{CC}$, Spielman A. Seasonal variation of transmission risk of Lyme disease and human babesiosis. Am F Epidemiol 1987; 126:1187-9.

17 O'Neill PM, Wright DJM. Lyme disease. Br $\mathcal{J}$ Hosp Med 1988;40:284-9.

18 Malane MS, Grant-Kels JM, Feder HM, Luger SW. Diagnosis of Lyme disease based on dermatologic manifestations. Ann Int Med 1991;114:490-8.

19 Millner M, Schimek MG, Spork D, Schnizer M, Stanek G. Lyme borreliosis in children. Eur $\mathcal{F}$ Pediatr 1989;148: 527-30.

20 Naglo A, Wide K. Borrelia infection in children. Acto Paediatr Scand 1989;78:918-22.

21 Culp RW, Eichenfield AH, Davidson RS, Drummond DS, Christofersen MR, Goldsmith DP. Lyme arthritis in children. F Bone foint Surg [Am] 1987;69-A:96-9.

22 Nadal D, Gundelfinger R, Flueler U, Boltshauser E. Acrodermatitis chronica atrophicans. Arch Dis Child 1988;63: $72-4$

23 Steere AC, Bartenhagen NH, Craft JE, et al. The early clinical manifestations of Lyme disease. Ann Int Med 1983;99: cal manif.

24 Schmidt R, Kabatzki J, Hartung S, Ackermann J. Erythema chronicum migrans disease in the Federal Republic of Germany. Zentralbl Bakteriol Mikrobiol Hgy [A] 1986;263: G35-41.

25 Banach JL, Coleman JL. Clinical and geographic features of Lyme disease in New York. Zentralbl Bakteriol Mikrobiol Hgy [A] 1986;263:477-82. 
26 Bigaignon G, Gubau P, Desmyter J, Vandepitte J. Lyme borreliosis in Belgium. Lancet 1987; i:557.

27 Schlesinger PA, Duray PH, Burke BA, Steere AC, Stillman MT. Maternal fetal transmission of Iyme disease spirochaete Borrelia burgdorferi. Ann Int Med 1985;103:67-8.

28 Nadal D, Hunziker UA, Bucher UA, Hitzig WH, Duc G. Infants born to mothers with antibiotics against Borrelia burgdorferi at delivery. Eur $\mathcal{F}$ Pediatr 1989;148:426-7.

29 Preac-Mursic V, Wilske B, Schierz G. European Borreli burgdorfer isolated from humans and ticks cultural conditions and antibiotic susceptibility. Zentralbl Bakterio Mikrobiol Hgy [A] 1986;263:1 12-8.

30 Magnarelli LA. Laboratory diagnosis of Lyme disease. Rheum Dis Clin North Am 1989;15:735-45.

31 Dattwyler RJ, Luft BJ. Immunodiagnosis of Lyme borreliosis. Rheum Dis Clin North Am 1989;4:727-33.

32 Karlsson M, Stiernstedt G, Granstrom M, Asbrink E, Wretlind $B$. Comparison of flagellum and sonicate antigen for serological diagnosis of Lyme borreliosis. Eur $\mathcal{J}$ Clin Microbiol Infect Dis 1990;3:169-77.

33 Hansen K, Asbrink E. Serodiagnosis of erythema migran and acrodermatitis chronica atrophicans by Borrelia burgand acrodermatitis chronica atrophicans by Borrelia burgdorferi flagellum enzyme-linked

34 Cutler SJ, Wright DJM. Comparison of immuofluorescent and enzyme linked immunosorbent assays for diagnosing F Clin Pathol 1989;42:869-71.

35 Nadal D, Taverna Ch. Hitzig WH. Immunoblot analysis of antibody binding to polypeptides of Borrelia burgdorferi in children with different clinical manifestations of Lym disease. Pediatr Res 1989;4:377-82.

36 Dattwyler RJ, Volkman DJ, Golightly MG, Falldorf PA Thomas J. Seronegative Lyme borreliosis after early antibiotic treatment. Arthritis Rheum 1987;30:S36.

37 Fahrer H, van der Linden SM, Sauvain M, Gern L, Zhioua $\mathrm{E}$, Aeschlimann A. The prevalence and incidence of clinical and asymptomatic Lyme borreliosis in a population at risk. f Infect Dis 1990;163:305-10.

38 Rosa PA, Schwan TG. A specific and sensitive assay for the Lyme disease spirochete Borrelia burgdorferi using the pyme disease spirochete Borrelia burgdorferi using the

39 Rosa PA, Schwan TG. Polymerase chain reaction analyses identify two distinct classes of Borrelia burgdorferi $\mathcal{f}$ Clin

40 Goodman JL, Jurkovich P, Kramber JM, Johnson RC Molecular detection of persistent Borrelia burgdorferi in the urine of patients with active Lyme disease. Infec Immunol 1991;59:269-78.

41 Ewen PW, Ackroyd JF. Allergic reactions to drugs. In Wright DJM, ed. Immunology of sexually transmitted diseases. Lancaster: MPT Press, 1978:244-6.

42 Johnson RC, Kodner C, Russell $M$. In vitro and in vivo susceptibility of the Lyme disease spirochaete, Borrelia burgdorferi to four antimicrobial agents. Antimicrob Agents Chemother 1987;31:164

43 Preac-Murisc V, Wilske B, Schierz G, Holmburger E. In vivo and in vitro susceptibilities of Borrelia burgdorferi. Eur fClin Microbiol 1987;6:424-6.

44 Preac-Murisc V, Wilske B, Schierz G, Sub E, Grob B. Comparative antimicrobial activity of new macrolides against Borrelia burgdorferi. Eur f Clin Microbiol Infect Dis against Borre $1989 ; 8: 651-2$.

45 Steere AC, Green J, Hutchinson GJ, et al. Treatment of Lyme disease. Zentralbl Bakteriol Mikrobiol Hgy [A] 1987;263: 352-6.

46 Weber K, Preac-Murisc V, Neubert U, et al. Antibiotic therapy of early European Lyme borreliosis and acroderma- titis chronic atrophicans. Ann $N Y$ Acad Sci 1988;539: $324-46$

47 Luft BJ, Volkman DJ, Halperin JJ, Dattwyler RJ. New chemotherapeutic approaches in the treatment of Lyme borreliosis. Ann NYAcad Sci 1988;539:352-61.

48 Dattwyler RJ, Volkman D, Conaty S, Gorevic P, Luft B. Ampxycillin plus probenecid compared to doxycycline for the treatment of erythema migrans. Arthritis Rheum 1990; 33(Suppl):S85.

49 Rahn DW, Malawista SE. Lyme disease: recommendations for diagnosis and treatment. Ann Int Med 1991;114:472-81.

50 Baumhackl U, Kristoferistsch W, Sluga E, Stanek G. Neurological manifestations of Borrelia burgdorferi infections: the enlarged clinical spectrum. Zentralbl Bakteriol Mikrobiol Hgy [A] 1987;263:334-6.

51 Dotevall L, Alestig K, Hanner P, Norkrans G, Hagberg L. The use of doxocycline in nervous system Borrelia burgdorferi infection. Scand $\mathcal{F}$ Infect Dis 1988;53:74-9.

52 Dotevall $\mathrm{L}$, Hagberg $\mathrm{L}$. Penetration of doxycycline into cerebrospinal fluid in patients treated for suspected Lyme neuroborreliosis. Antimicrob Agents Chemother 1989;33: 1078-80.

53 Baranton G, Perolat P, Dufresne Y, Postic D, Quentin R, Fouquet B, Isolation of Borrelia burgdorferi in the spinal Fouquet B, Isolation of Borrelia burgdorferi in the spinal fluid of

54 Wise R. Antimicrobial agents: a widening choice. Lancet 1987; ii: $1251-4$.

55 Chandrasekar P, Rolston K, Smith B, LeFrock J. Diffusion of ceftriaxone into the cerebrospinal fluid of adults. f Antimicrob Chemother 1984;14:427-30.

56 Dattwyler RJ, Halperin JJ, Volkman DJ, Luft BJ. Treatment of late Lyme borreliosis-randomised comparison of ceftriaxone and penicillin. Lancet 1988;i:1191-4.

57 Pfister HW, Einhaupl KM. Neurological complications of Lyme-borreliosis: outpatient treatment with once daily ceftriaxone. Abstract IV. International Conference on Lyme Borreliosis. Stockholm, 1990 Book A: 165.

58 Pfister HW, Prec-Mursic V, Wilske B, Schielke E, Sorgel F, Einhaupl KM. Randomised comparison of ceftriaxone and cefotaxime in Lyme neuroborreliosis. F Infect Dis 1991; 163:311-8

59 Schaad UB, Wedgewood-Krucko J, Tschaeppeler H. Reversible ceftriaxone-associated biliary pseudolithiasis in children. Lancet 1988;ii:1411-3.

60 Dattwyler RJ, Volkman DJ, Goliath MG, Falldorf PA, Thomas J. Seronegative Lyme boreliosis after early antibiotic treatment. Arthritis Rheum 1987;30(suppl 4):S36.

61 Pal GS, Baker JT, Wright DJ. Penicillin resistant borrelia encephalitis responding to cefotaxime. Lancet $1988 ; \mathrm{i}: 50-51$

62 Steere AC, Green J, Schoen RT, et al. Successful parenteral penicillin therapy of established Lyme arthritis. $N$ Engl f Med 1985;312:869-74.

63 Liu NY, Dinerman H, Levin RF, et al. Randomised trial of doxycycline versus amoxicillin probenecid for the treatmen of Lyme arthritis: treatment of non responders with iv penicillin or ceftriaxone (abstract). Arthritis Rheum 1989; 32(suppl): $\$ 32$

64 Steere AC, Dwyer E, Winchester R. Association of chronic lyme arthritis with HLA-DR4 and HLA-DR2 alleles. lyme arthritis with HEnglf Med 1990;323:219-23.

65 Teklu B, Habte-Michael A, Warrell DA, White NJ, Wright DJM. Meptazinol diminishes the Jarisch-Herxheimer DJM. Meptazinol diminishes the Jarisch-H.

66 Simon MM, Schaible UE, Wallich R, Kramer MD. A mouse model for Borrelia burgdorferi infection: approach to a vaccine against Lyme disease. Immunol Today 1991;12:11-6. 